\title{
Desafíos pendientes para la definitiva implantación de la evaluación del desempeño
}

Pedro Padilla Ruiz

DOI: https://doi.org/10.47623/ivap-rvap.109.2017.1.14

\begin{abstract}
Sumario: I. Introducción: 1. La necesidad de aplicar la evaluación del desempeño en la Administración Pública.-II. Principales obstáculos existentes en la gestión del empleo público para la implantación de la evaluación del desempeño: 1. Inexistencia de planificación estratégica que permita saber qué evaluar. 2. La desnaturalización del complemento de productividad. 3 . Un sistema de carrera artificial que no ha cumplido su función. 4. La desmotivación del empleado público. 5. La olvidada institución de la formación del empleado público.III. Conclusiones.-IV. Bibliografía.
\end{abstract}

\section{Introducción}

La aprobación del EBEP por medio de la Ley $7 / 2007$ supuso un punto de inflexión en la regulación del empleo público en España, aportando no solo el necesario marco legal que exigía la Constitución desde hacía casi treinta años sino sobre todo estableciendo un nuevo modelo de calidad en la forma de actuar de nuestras Administraciones a través de su personal. El Estatuto incluyó algunas novedades destacables como motores de ese cambio. Entre ellas podemos mencionar la carrera horizontal, el código ético y de conducta y, sobre todo, la evaluación del desempeño(1), que constituye el elemento nuclear en la aplicación de esas y otras herramientas y mecanismos que el legislador ha puesto a disposición de aquellas con la clara intención de poner en valor, por fin, a quienes representan el verdadero cerebro y músculo de las Administraciones, los empleados públicos (2). El objetivo del EBEP ha sido, por tanto,

(1) Sobre el concepto y la aplicación de la evaluación del desempeño en la Administración Pública puede leerse a PADILLA RUIZ, Pedro, Gestión del empleo público. La evaluación del desempeño en la mejora de la eficiencia administrativa. Bosch Editor, Barcelona, 2016.

(2) A los meros efectos expositivos hablaremos de empleados públicos para hacer referencia tanto a los hombres como a las mujeres que forman parte de las Administraciones Públicas. En el mismo sentido aglutinador utilizamos el sustantivo neutro ciudadano, funcionario, etc. para referirnos a ambos sexos. 
mejorar la motivación y la productividad de su capital humano como medio para lograr la satisfacción del ciudadano, que es - a la postreel fin último de las Administraciones Públicas dentro del nuevo paradigma de la calidad total.

Sin embargo, la entrada en vigor del EBEP coincidió con una profunda crisis que llevó a la inaplicación de muchas de sus novedades y al establecimiento de unas medidas drásticas, en muchos casos contrarias a los postulados del mismo y que no tuvieron en cuenta las potencialidades que realmente aportaba a la reforma del empleo público. Una de las principales afectadas fue, precisamente, la evaluación del desempeño, que no se trató seriamente ni por la Administración General del Estado (AGE) ni por las Comunidades Autónomas, como recuerda PALOMAR OLMEDA (3), lo que obviamente afectó también a las Entidades Locales (4). Como en tantas otras ocasiones, la justificación dada fue la falta de recursos económicos y el coste que la implantación de la evaluación del desempeño supondría, optándose por aplicar medidas más directas y drásticas como la reducción del número de empleados públicos a través de despidos masivos (que en muchas ocasiones se han visto revocados por los Tribunales), amortización de plazas (5), reducción y congelación salarial(6), incremento de horas de trabajo o reducción de derechos sociales y sindicales, como ha tenido ocasión de estudiar RODRÍGUEZ ESCANCIANO (7).

Estos problemas y las soluciones "de urgencia» que se adoptaron nos demuestran dos cosas: la poca consideración que tradicionalmente ha tenido el capital humano entre los responsables de recursos humanos, a pesar de constituir el más importante motor que impulsa nuestras organizaciones públicas gracias a su talento y habilidades; y la falta de visión,

(3) PALOMAR OLMEDA, Alberto, "Impasse y deterioro del marco jurídico. ¿Habrá que cambiar el EBEP antes de aplicarlo?», en Revista Vasca de Gestión de Personas y Organizaciones Públicas, n. ${ }^{\circ} 3$, 2012, pp. 78-93.

(4) BOLTAINA BOSCH, Xavier, "El empleo público local ante la crisis», en Debates locales, n. ${ }^{\circ} 2$, 2011, pp. 288.; MAURI MAJÓS, Joan. «Medidas de ajuste para hacer frente a la crisis en el empleo público local: una perspectiva desde la función pública", en Cuadernos de Derecho Local, n. ${ }^{\circ} 26$. Junio, 2011, pp. 55-86.

(5) Como ocurrió en Castilla la Mancha, principalmente en 2013.

(6) Sobre la reducción salarial recuérdese la eliminación de la paga extraordinaria de diciembre de 2012 por el Real Decreto-Ley 20/2012 con efectos retroactivos, y que los Tribunales han revocado parcialmente en cuanto a los días de aplicación retroactiva, y que supuso un importante varapalo no solamente económico sino también creador de inseguridad jurídica y desmotivación.

(7) RODRÍGUEZ ESCANCIANO, Susana, "Incidencia de la reforma laboral de 2012 sobre el empleo público. En especial, las medidas de reajuste de efectivos", en Boletín de Función Pública del INAP, n. ${ }^{\circ}$ 8, 2012, pp. 5-13. También RODRíGUEZ ESCANCIANO, Susana. «Posibilidades para el reajuste de efectivos en el ámbito público a la luz de la reforma laboral de 2012", en Cuadernos de derecho local, n. ${ }^{\circ} 31,2013$, pp. 40-69. 
iniciativa y del coraje suficientes por parte de los gestores públicos para enfrentarse a los verdaderos desafíos estructurales de nuestro empleo público y eliminar, o al menos limitar, las barreras que impiden aplicar la evaluación y el resto de reformas previstas por el EBEP.

No hemos de pasar por alto que la mejora de los resultados de la Administración no solo pasa por aplicar nuevas técnicas o herramientas a la gestión pública, sino que también deben removerse los obstáculos preexistentes, algunos de los cuales veremos a continuación.

\section{La necesidad de aplicar la evaluación del desempeño en la Administración Pública}

No obstante haber pasado por una importantísima crisis económica y estar sufriendo otra de credibilidad de lo público y de deslegitimación de la Administración, como señala ARENILLA SAEZ(8), no cabe duda de la posibilidad, o más bien necesidad, de desarrollar de una vez la evaluación del desempeño dentro de un imprescindible proceso de transformación y racionalización permanente de la Administración (9). Obviamente supondrá un importante esfuerzo de adaptación de las estructuras actuales a los nuevos modelos de gestión del empleo público, además de cambiar la vigente concepción que se tiene de cualquier innovación administrativa. Hemos de pasar de considerar esas técnicas y herramientas más propias de otros ámbitos como algo totalmente ajeno a la Administración o como un gasto, para reconocerlas y asimilarlas con las oportunas adaptaciones a las exigencias legales y de garantía de derechos, teniendo en cuenta que el legislador ha confiado en ellas al plasmarlas en el EBEP porque tienen ya un largo recorrido en el entorno privado, han sido probadas y son sobre todo una verdadera inversión de futuro.

(8) ARENILLA SÁEZ, Manuel, Crisis y reforma de la Administración Pública. Netbiblo, Oleiros (Coruña), 2011. p. 17. Sobre la pérdida de legitimación de la Administración por una idea generalizada de que lo hace peor que el sector privado y la necesidad de tener más en cuenta al ciudadano, léase a ARENILLA SÁEZ, Manuel. "Legitimidad y eficacia de la Administración pública», en Gestión y análisis de políticas públicas, vol. Enero-Agosto, n. ${ }^{\circ}$ 26-27, 2003, pp. 71-102. Sobre la legitimación de la Administración léase a SCHMIDT-ABMANN, Eberhard. "La legitimación de la Administración como concepto jurídico", en Documentación Administrativa, n. ${ }^{\circ}$ 234, 1993, pp. 163-230. También es de interés BAÑÓN, Rafael, "La legitimidad de la Administración Pública», BAÑÓN, R.Y E. CARRILLO, (COMPS). La nueva Administración Pública. Alianza, Madrid, 1997. Asimismo, PAREJO ALFONSO, Luciano, Crisis y renovación en el Derecho Público. Edit. Ciudad Argentina, Buenos Aires, Madrid, 2003. p. 78. PAREJO ALFONSO, Luciano, Eficacia y Administración: tres estudios. INAP, Madrid, 1995. p. 19. RAMIÓ MATAS, Carles, Administración pública y crisis institucional: estrategias de reforma e innovación para España y América Latina. Tecnos, Madrid, 2015.

(9) ORTEGA ÁLVAREZ, Luis, "¿Es posible desarrollar el EBEP en tiempos de crisis?», en FUENTETAJA PASTOR, Jesús Ángel y CANTERO MARTÍNEZ, Josefa (Dir.), Crisis económica y función pública. Aranzadi Thomson Reuters, Cizur Menor (Navarra), 2012, pp. 11-20. 
Lo que no podemos hacer es alegrarnos por la aprobación del EBEP y sus novedades, creyendo que la introducción a nivel legal de la evaluación del desempeño va a solucionar una parte importante de los problemas del empleo público, pero al mismo tiempo dejar transcurrir los años sin que las Administraciones se hayan puesto en serio a trabajar en el diseño y puesta en práctica de un modelo adecuado, a pesar de existir en varias Comunidades Autónomas leyes adaptadas al Estatuto que recogen esta institución. Hasta el momento solo podemos hablar de un sistema probado y en pleno funcionamiento, el del Principado de Asturias, amén de otro en fase de prueba piloto durante varios años como el de la AGE. Por lo demás, y al margen de algunas experiencias aisladas en entidades locales no podemos decir que la evaluación ni el EBEP hayan tenido el éxito que se esperaba, e insistimos en que más que por falta de medios se ha debido a carencia de verdadera voluntad por impulsar las reformas necesarias y remover los obstáculos existentes dentro de la gestión del empleo público.

\section{Principales obstáculos existentes en la gestión del empleo público para la implantación de la evaluación del desempeño}

Esa falta de una verdadera intención por establecer la evaluación, aunque fuese de manera parcial o en "modo piloto", se ha debido también - como indicábamos - a una serie de dificultades inherentes a la estructura y funcionamiento de las Administraciones, arrastrados desde hace décadas y que no se han tratado de solventar completamente por más que el legislador anterior al EBEP hubiese realizado ciertas previsiones (aunque en ocasiones parciales) para mejorar la gestión del empleo público. Unos problemas que constituyen no sólo obstáculos o verdaderas amenazas para la aplicación exitosa de sistemas de evaluación del desempeño, sino que son a la vez parte de los propios inconvenientes que esta herramienta trata de solucionar.

A continuación vamos a revisar algunos de los más importantes, pues sería prolijo estudiar todas y cada una de las posibles dificultades a las que se enfrenta la implantación de la evaluación, pretendiendo centrarnos únicamente en las que han tenido un carácter más estructural, se encuentran más arraigadas en la gestión del personal (10) y tienen una relación más directa con la herramienta evaluadora. No obstante, debemos mencionar también que la propia novedad de la evaluación del desem-

(10) Hoy en día se prefiere el término gestión de personas o del personal frente al más tradicional de gestión de recursos humanos, para hacer hincapié en el verdadero valor que tiene el capital humano en cualquier organización. 
peño trae consigo una serie de temores y dudas acerca de su aplicación a un entorno para el que es desconocida y que suponen una cierta limitación a su desarrollo, como las normales reticencias de los empleados públicos hacia sus verdaderos fines, quién y cómo se asumirá el rol de evaluador, cómo se realizará la evaluación de y por los directivos públicos, la falta de liderazgo y de cultura administrativa, o cómo evaluar ciertos trabajos, sin olvidar la debida garantía de los derechos de los empleados públicos.

\section{Inexistencia de planificación estratégica que permita saber qué evaluar}

Queremos comenzar este breve repaso con uno de los principales obstáculos para una gestión integral del personal y del que deriva, al menos en parte, el resto de problemas que limitan el avance de la gestión del empleo público: la planificación estratégica.

La Administración Pública española - en términos generales - ha carecido de un diseño o planeamiento de sus objetivos como organización, así como de una subsecuente planificación de sus recursos humanos. Debemos recordar, con PALOMAR OLMEDA, que la planificación es -en cierto modo- establecer los objetivos organizacionales de una manera clara, priorizarlos y coordinarlos entre los distintos departamentos, sin olvidar la necesidad de conectarlos con los medios disponibles para poder llevarlos a cabo de manera óptima(11).

En este sentido no debe parecernos extraño escuchar actualmente términos novedosos en el ámbito público como la necesidad de que las organizaciones cuenten con una misión y visión definidas acerca de lo que pretenden ser y hacia dónde quieren dirigirse - que sepan qué deben hacer (su misión) y cómo la entienden (visión) - dentro del objetivo teleológico y constitucionalmente fijado de alcanzar el bienestar general, amén de la satisfacción del ciudadano, y sin perder de vista el tercer concepto que acompaña a los dos anteriores, los valores que marcan su seña de identidad y que quiere proyectar hacia ese mismo ciudadano(12). Pode-

(11) PALOMAR OLMEDA, Alberto, Derecho de la función pública. Régimen jurídico de los funcionarios públicos. Dykinson, Madrid, 2009. p. 159 y 160 y ss. Véase también PALOMAR OLMEDA, Alberto, Planificación del empleo público e instrumentos de flexibilización y racionalización. 1. ${ }^{\text {a }}$ edic., Lex Nova, Valladolid, 2015.

(12) Un buen ejemplo de la importancia que están alcanzando los conceptos misión y visión en nuestras Administraciones Públicas lo hallamos en el INAP, AEVAL, la Agencia Estatal de Meteorología o la Agencia Tributaria de Murcia. En la Administración local podemos destacar el Ayuntamiento de Alcobendas, al ser uno de los más implicados con la modernización administrativa, o el de Madrid. Todos estos casos contemplan dichos conceptos en sus sedes electrónicas. 
mos recordar aquí las palabras de NIETO GARCÍA a cuenta de la necesidad de que la Administración sepa hacia dónde ir: «si no sabemos lo que queremos ni a dónde pretendemos ir, ponerse a caminar es perder el tiempo" (13) .

El Informe de la Comisión tuvo ocasión de mencionar el problema de la carencia de planificación como uno de los fundamentales en materia de empleo público al destacar "la práctica inexistencia de planificación estratégica de recursos humanos y la debilidad de los mecanismos de gestión" (14). Así es, la falta de planificación de los objetivos generales de la Administración impide establecer los más concretos, diseñar su actuación, la estructura y los medios personales, económicos y materiales más adecuados para llevar a cabo su misión. Al mismo tiempo, no tener claros los objetivos como organización conlleva indefectiblemente que no exista ni se entienda bien lo que es la cultura organizacional, de lo público, lo cual supone que no se lleve a cabo algo esencial para el éxito de cualquier modelo mínimamente organizado de gestión pública y del personal: poner a todos sus miembros mirando en la misma dirección, sabiendo que forman parte de un todo y que su trabajo, por sencillo que parezca, se dirige a un fin superior que es servir a los ciudadanos.

A estas dificultades se le añade, en ocasiones, la de no contar con un dimensionamiento óptimo de las plantillas y una gestión interna del personal que sea coherente, eficiente y en la que existan las adecuadas sinergias entre sus diferentes áreas(15) para dirigirlas hacia el objetivo común de la organización, y donde no podemos perder de vista un elemento también esencial dentro de dicha gestión, relacionado con los objetivos de la organización, su estructura y funcionamiento: los perfiles de puestos de trabajo. Una organización planificadora, que sabe hacia

(13) NIETO GARCÍA, Alejandro, "Un primer paso para la reforma de la Administración española", en BAENA DEL ALCÁZAR, MARIANO (DIR.), La reforma del Estado y de la Administración española. INAP, Madrid, 2013, pp. 163-184.

(14) SÁNCHEZ MORÓN, Miguel, CASES MÉNDEZ, José Ignacio, et al., Informe de la Comisión para el estudio del Estatuto Básico del Empleado Público. INAP [versión electrónica], Madrid, 2005. p. 13. El estudio de la planificación estratégica en la Administración española es relativamente reciente, pues es a finales de los 80 y comienzo de los 90 del pasado siglo cuando comienzan a surgir estudios que tratan de dar respuesta a las necesidades de la gestión de personas en aquellas. Entre otros podemos destacar PRATS CATALÁ, J., "Política, gestión y administración de recursos humanos en las Administraciones públicas», en Documentación administrativa, n. ${ }^{\circ} 210,1987$, pp. 121-134. RODRÍGUEZ FERNÁNDEZ, Andrés, Los recursos humanos en las administraciones públicas. Tecnos, Madrid, 1995.; CORTÉS CARRERES, J.V., Manual práctico de gestión de recursos humanos en la Administración Local. Dykinson, Madrid, 2001. VILLORIA MENDIETA, Manuel y DEL PINO MATUTE, Eloísa, Manual de gestión de recursos humanos en las Administraciones Públicas. 2. ${ }^{a}$ edic., Tecnos, Madrid, 2000.; RODRÍGUEZ FERNÁNDEZ, Andrés, Dirección y gestión de los recursos humanos en las Administraciones Públicas. Instituto Andaluz de Administración Pública, Sevilla, 2001.

(15) Dependiendo de los autores, se suele habla de unas 18-21 áreas o funciones de gestión del personal, de las que podemos destacar las de reclutamiento y selección, formación, retribución, promoción, evaluación del desempeño, motivación y satisfacción, prevención de riesgos laborales... 
dónde quiere dirigirse y lo que necesita exactamente para ello, con una estructura compacta y que cuenta con el personal adecuado en cada puesto, requiere que las funciones y tareas estén correctamente definidas, lo cual es también una condición para el éxito de la evaluación del desempeño, que se centra en la medición de las tareas (más relevantes) del empleado en su puesto.

La planificación de recursos humanos fue introducida en la Ley 30/1984, de Medidas para la reforma de la Función Pública (LMRFP) por la Ley $22 / 1993$, de medidas fiscales, de reforma del régimen jurídico de la función pública y de la protección por desempleo. Dicha novedad apareció a través de los planes de empleo para hacer frente a la crisis de los años 90 , pero a pesar de su relativamente temprana introducción en nuestro ordenamiento, como ha venido ocurriendo en nuestro derecho con otras herramientas no se llegó a extender su aplicación debido, según RODRÍGUEZ ESCANCIANO o PALOMAR OLMEDA, a sus limitadas expectativas(16). Nuevamente ha faltado algo tan esencial como visión de futuro para abordar los problemas existentes en nuestro empleo público.

EI EBEP ha sido consciente de la necesidad de contar con una adecuada planificación si se quieren lograr realmente sus previsiones y por ese motivo la vuelve a introducir, esta vez tratando de darle más peso con el fin de acomodarla a las exigencias generales de su articulado en lo que debe ser el empleo público del futuro, considerando la «eficacia en la planificación y gestión de los recursos humanos" como uno de sus fundamentos de actuación (art. 1.3.f) (17).

La evaluación del desempeño pretende jugar aquí un papel esencial porque requiere la existencia de una idea clara de la misión fundamental de la Administración con el fin de enfocar sus esfuerzos y el diseño de su actuación en la parte del desempeño del empleado público que interesa para mejorarlo y controlar que cumple lo planificado. Recordemos que si la Administración quiere considerarse $-y$ que los ciudadanos la veancomo una organización de calidad e incluso excelente (ya existen casos) deberá aplicar procesos de mejora continua en los que el primer paso es planificar los objetivos que pretende alcanzar y posteriormente medir lo que se hace para saber si aquellos se cumplen o no, e ir mejorando la actuación administrativa.

(16) RODRÍGUEZ ESCANCIANO, Susana, "Los planes de empleo como medida de reestructuración administrativa: dificultades de aplicación práctica», en Las relaciones laborales en la reestructuración y el saneamiento de empresas : XVI Congreso Nacional de Derecho del Trabajo y de la Seguridad Social, 19 y 20 de mayo de 2005, Granada, 2006, pp. 297-322. PALOMAR OLMEDA, Alberto. Derecho de la función pública. Régimen jurídico de los funcionarios públicos, Dykinson. Madrid, 2009. p. 164.

(17) A la planificación le dedica el Capítulo I (Planificación de recursos humanos; artículo 69 y siguientes) delTítulo V (Ordenación de la actividad profesional). 
En este sentido es conveniente mencionar que cuando hablamos de mejora continua se viene aplicando en las organizaciones el denominado ciclo Deming (PDCA por sus siglas en inglés), que supone planificar, ejecutar, controlar lo ejecutado (medirlo, evaluarlo) y hacer los ajustes necesarios de acuerdo a lo hecho y medido con el fin de volver a empezar planificando nuevamente con las mejoras necesarias. Como vemos, la evaluación juega un papel esencial para medir lo que se hace y obtener la necesaria retroalimentación que permita controlar la marcha de lo planificado y dirigirla hacia el éxito. Esa evaluación puede ser tanto del desempeño del empleado como de los resultados organizacionales, ya que da igual el ámbito al que nos refiramos, pues lo que se planifique en la cúspide se irá distribuyendo a lo largo de toda la estructura hasta la base, y los resultados de la evaluación de cada empleado irán subiendo en un "viaje de vuelta» por esa misma estructura para conocer si la planificación general ha dado los frutos organizativos previstos.

\section{La desnaturalización del complemento de productividad}

El complemento de productividad, como incentivo económico a un mayor rendimiento del empleado, ha sido una de las más importantes y fracasadas herramientas que el legislador puso en manos de la Administración para mejorar la calidad de sus resultados. En efecto, la LMRFP reguló el complemento de productividad aunque de manera parcial, pues si bien se especificaban los supuestos generales (el tipo de actuación profesional) que debían considerarse para otorgarlo, ampliando la legislación anterior, no se establecía - sin embargo - un imprescindible sistema de control que permitiera acreditar realmente su nivel de cumplimiento al que conectar unas consecuencias retributivas adecuadas. Además, tampoco se preveían unos estándares de desempeño que permitieran saber lo que era un trabajo bien hecho.

Lo que hace el EBEP al introducir(18) la evaluación del desempeño ha sido, en suma, completar una ordenación sorprendentemente inacabada en relación con dicho complemento de productividad y, en general, abordar definitivamente la medida del desempeño previendo unas consecuencias concretas motivadoras y fundamentadas que coadyuven a mejorar la actuación profesional y con ello la eficacia y eficiencia de toda la Administración.

(18) Realmente el EBEP no introduce la evaluación del desempeño y no podemos decir que sea, en puridad, una verdadera novedad pues ya existían algunas experiencias anteriores a su aprobación original, como reconoce su Exposición de motivos. Podemos mencionar las de la Diputación de Barcelona, Justicia, Universidades, o de ciertas Agencias estatales. 
Ese problema no pasó inadvertido para la Comisión de Estudio del EBEP, en cuyo Informe incidió en que la aplicación del complemento de productividad "ha sido uno de los puntos más débiles del sistema, ya que no ha cumplido la función de incentivación de los empleados públicos por la obtención de resultados a que estaba Ilamado" (19). Precisamente uno de los principales problemas en el origen de la cuestión ha sido la falta de concreción del sistema de incentivos existente en nuestras Administración, comenzando por la consideración exclusiva del estímulo de carácter meramente económico y continuando con la carencia de definición del significado y contenido de dicha remuneración, pues como indica CASTILLO BLANCO, al margen de distinguir los diferentes tipos de retribuciones, no se definen estas (cuestión que tampoco resuelve el EBEP) como sí hace, por contra, la legislación laboral (20).

Esa falta de un marco conceptual adecuado no es una cuestión baladí y parte principalmente de la consideración de la retribución como una simple contraprestación por el trabajo dentro de una concepción burocrática, rigurosa y hasta tylorista del mismo(21), pretendidamente tendente al igualitarismo y a la "homogeneidad de los complementos y de la productividad", en palabras de MANZANA LAGUARDA(22). Se trata, ciertamente, de una visión que CASTILLO BLANCO también ha denominado "capitidisminuida", quizás demasiado limitada de lo que debe considerarse realmente la función pública al verse más en su aspecto meramente normativo, como parte necesaria de la estructura administrativa(23), sin tener presente los imprescindibles elementos personales que inciden en cualquier relación laboral o profesional.

Tampoco podemos olvidar que, de acuerdo a las más destacadas teorías sobre la psicología del trabajo y de las organizaciones en materia de motivación, por lo que respecta a la gestión del personal la retribución

(19) SÁNCHEZ MORÓN, Miguel, CASES MÉNDEZ, José Ignacio, et al., Informe de la Comisión para el estudio del Estatuto Básico del Empleado Público. INAP [versión electrónica], Madrid, 2005. p. 151. Apartado 70, que a la sazón titula «El sistema legal de retribuciones: disfunciones y carencias".

(20) CASTILLO BLANCO, Federico A., El sistema retributivo en la función pública española. Marcial Pons, Madrid, 2002. p. 9. La definición del salario en el ámbito laboral se establece en el artículo 26 del Real Decreto Legislativo 2/2015, de 23 de octubre, por el que se aprueba el texto refundido de la Ley del Estatuto de los Trabajadores.

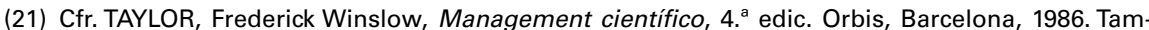
bién puede leerse esta obra gratuitamente y en su versión original (The Principles of Scientific Management) a través del Proyecto Gutenberg (http://www.gutenberg.org).

(22) MANZANA LAGUARDA, Rafael, La nueva función pública: una injustificable demora. Especial referencia a la ley valenciana 10/2010. Tirant lo Blanch, Valencia, 2013. p. 15.

(23) CASTILLO BLANCO, Federico A., El sistema retributivo en la función pública española. Marcial Pons, Madrid, 2002. p. 10. 
(que recordemos no es solamente la dineraria) va mucho más allá de esa mera contrapartida a cambio de trabajo, sino que constituye una verdadera herramienta motivadora del buen desempeño y como reconocimiento a otras aportaciones del empleado como las propuestas de mejora de procesos, de ahorro de costes, etc. No obstante, de acuerdo con esas mismas teorías también hemos de recordar que la pecuniaria no es la única e, incluso, deberían estudiarse otros alicientes, como ha señalado PADILLA RUIZ(24).

Además de estas consideraciones de carácter más bien teórico hemos de indicar que el sistema de incentivos establecido por la LMRFP se quedó a medio camino en lo que debería haber sido un completo sistema de estímulo a la productividad, pues faltó un tercer elemento intermedio, el control, para dar lugar al verdadero y perfecto círculo desempeño-control-recompensa. Esto ha llevado, sin duda, a crear una serie de circunstancias derivadas que han ayudado a desnaturalizar el complemento, entre las que podemos destacar primeramente la falta de criterios claros (los estándares que mencionábamos anteriormente) para medir el desempeño; poca voluntad o capacidad por parte de los gestores públicos y responsables de recursos humanos para aplicarlo correctamente, unido a una mal entendida discrecionalidad de la Administración a la hora de regularlo, como han recordado tanto BACIGALUPO SAGUESSE, BELTRÁN DE FELIPE o SÁNCHEZ MORÓN como la Jurisprudencia(25), o su desconexión con otras políticas en materia de personal que lo conectaran hacia el logro de los objetivos generales de la Administración. Precisamente, esa falta de unidad en el entorno de la gestión del personal ha sido otro de los graves problemas del empleo público y que la evaluación del desempeño puede ayudar a resolver como herramienta que coordine y permita crear unas necesarias sinergias entre las diferentes áreas de la mencionada gestión.

En definitiva, se ha llegado a un modelo totalmente desnaturalizado, carente de sentido y que no ha acertado a la hora de aprovechar las oportunidades que ofrecía aun siendo un modelo incompleto. Más bien ha lle-

(24) PADILLA RUIZ, Pedro, Gestión del empleo público. La evaluación del desempeño en la mejora de la eficiencia administrativa. Bosch Editor, Barcelona, 2016. p. 403 y ss.

(25) BACIGALUPO SAGGESE, Mariano, La discrecionalidad administrativa: estructura normativa, control judicial y límites constitucionales de su atribución. UNED, Tesis Doctoral, 1997. BELTRÁN DE FELIPE, Miguel, Discrecionalidad administrativa y Constitución. Tecnos, Madrid, 1995, SÁNCHEZ MORÓN, Miguel, Discrecionalidad administrativa y control judicial, Tecnos, Madrid, 1994. En cuanto a la Jurisprudencia podemos destacar la STS de 1 junio 1987, FJ $4 .^{\circ}$ : "estas retribuciones en las que se contempla la productividad de los funcionarios, Cuerpos o Escalas, ha de existir una cierta discrecionalidad en la Administración conocedora del funcionamiento de cada uno de los servicios, lo que no es causa alguna de discriminación sino de trato adecuado según las circunstancias de cada caso, que no son iguales en los diferentes puestos de trabajo". 
vado, en los casos más extremos, al conocido café para todos(26), en otros muchos para incentivar a quienes ya no podían ascender más en la carrera por encontrarse en los niveles superiores (27).

Recordemos que el artículo 23.3.c) LMRFP definió el complemento de productividad como aquella parte del salario destinada a «retribuir el especial rendimiento, la actividad extraordinaria y el interés o iniciativa con que el funcionario desempeñe su trabajo». Sin embargo, al no prever un sistema de medición de dicho desempeño serían las leyes de Presupuestos Generales del Estado las que anualmente, y al fijar la cuantía de las retribuciones de los empleados públicos, han tratado de completar el modelo al exigir la aplicación de criterios basados en causas objetivas y establecer que su reconocimiento no generaba derechos adquiridos (28).

Hemos de tener en cuenta que la naturaleza jurídica del complemento de productividad parte, como recuerda el Informe de la Comisión, de la consideración de lo que el funcionario hace y de cómo lo hace en su puesto de trabajo(29), tratando de incentivar un rendimiento mayor al

(26) Entre otros, GORRITI BONTIGUI, Mikel, "La Evaluación del Desempeño en las Administraciones Públicas Españolas», en Revista de Psicología del Trabajo y de las Organizaciones, vol. 23, n. ${ }^{\circ}$ 3, 2007, pp. 367-387. p. 372. CUENCA CERVERA, J. Javier, Manual de dirección y gestión de recursos humanos en los gobiernos locales. INAP, Madrid, 2012. El término "café para todos", sin embargo, fue acuñado dentro de los estudios para el desarrollo del proceso autonómico, como recuerda TEROL GÓMEZ, Ramón, "La Administración de las Comunidades Autónomas», Jaime RODRígueZ-ARANA MUÑOZ, (Dtor.), La Administración Pública española. INAP, Madrid, 2002. p. 320.

(27) Algunas de estas carencias son mencionadas por el Informe de la Comisión en su apartado 70. Sobre los problemas tradicionales del complemento de productividad también puede leerse, entre otros, a CASTILLO BLANCO, Federico A., "Luces y sombras del complemento de productividad: ¿un concepto retributivo inaplicado?", en Justicia administrativa: Revista de Derecho Administrativo, n. ${ }^{\circ} 8,2000$, pp. 5-24. pp. 5-24. CUENCA CERVERA, J. Javier, Manual de dirección y gestión de recursos humanos en los gobiernos locales. INAP, Madrid, 2012. CASTILLO BLANCO, Federico A., "Los derechos retributivos de los empleados públicos», en SÁNCHEZ MORÓN, Miguel y CASTILLO BLANCO, Federico A., Comentarios a la Ley del Estatuto Básico del Empleado Público. 2. ${ }^{a}$ edic., Lex Nova, Valladolid, 2008, pp. 229-321. PADILLA RUIZ, Pedro. «El complemento de productividad y la evaluación del desempeño en la Ley 7/2007. Hacia la calidad en la gestión pública», en El Consultor de los Ayuntamientos y de los Juzgados, n. ${ }^{\circ} 17,2008$, pp. 2867-2886.

(28) La Ley de Presupuestos General del Estado para 1985 (Ley 50/1984, de 30 de diciembre), primera que incluyera las previsiones de la LMRFP, estableció en su artículo 12 que la "apreciación de la productividad deberá realizarse en función de circunstancias objetivas relacionadas directamente con el desempeño del puesto de trabajo y la consecución de los resultados u objetivos asignados al mismo", determinándose por cada Departamento la cuantía individual que procediera.

Más recientemente, el artículo 23.1.E de la Ley 48/2015, de 29 de octubre, de Presupuestos Generales del Estado para el año 2016, fija como criterios que "La valoración de la productividad deberá realizarse en función de circunstancias objetivas relacionadas con el tipo de puesto de trabajo y el desempeño del mismo y, en su caso, con el grado de participación en la consecución de los resultados u objetivos asignados al correspondiente programa". Seguidamente también recuerda su carácter no periódico al no originar derechos en períodos posteriores.

(29) SÁNCHEZ MORÓN, Miguel, CASES MÉNDEZ, José Ignacio, et al., Informe de la Comisión para el estudio del Estatuto Básico del Empleado Público. INAP [versión electrónica], Madrid, 2005. N. ${ }^{\circ}$ 70. p. 150. 
normal (art. 10 Decreto 889/1972) o el especial rendimiento, la actividad extraordinaria y el interés o iniciativa con que el funcionario desempeña su trabajo (art. 23.3 LMRFP). Así pues, se trata realmente de un complemento eminentemente subjetivo o personal(30), lo que lleva aparejado uno de sus fundamentos esenciales, pues no puede ser ni periódico en el tiempo ni fijo en su cuantía.

Empero, a pesar de la reiteración y conocimiento de estas reglas poco se ha hecho por desarrollar modelos objetivos y que cumplieran realmente las expectativas puestas en una herramienta a priori positiva, lo que para CASTILLO BLANCO ha ocasionado unas inercias históricas que han llevado a las prácticas que se han venido produciendo y que desvirtuaron su función de motivación y de logro de la eficiencia administrativa (31).

En efecto, en no pocas ocasiones ha sido la propia Administración la que ha perpetuado el problema objetivando de tal modo esta institución que la ha transformado en un complemento salarial al uso incluido en la nómina mensual casi sin más, algo duramente criticado en no pocas ocasiones por autores como CASTILLO BLANCO, CONSUEGRA GINER o GIL GUILLÉN, así como por la propia Jurisprudencia(32). No obstante, tam-

(30) Por todas, la STS de 22 de diciembre de 2011, Sala $3^{a}$, FJ 10. ${ }^{\circ}$ : "el complemento de productividad retribuye aspectos subjetivos como el especial rendimiento, la actividad extraordinaria o el interés o iniciativa del funcionario en el desempeño de su cometidos y no otro tipo de aspectos de carácter objetivo ligados al puesto de trabajo que lo serían, en su caso, a través del complemento específico". Respecto a su carácter no fijo ni periódico, entre otras, STSJ de Madrid núm. 1227/2008 de 13 mayo, Sección $7 .^{a}$, FJ $2 .^{\circ}$ "en función de las notas que lo caracterizan en su configuración Legal, no tiene la consideración de complemento periódico o fijo en su contenido de tal forma que su percepción durante determinado período no genera en el perceptor un derecho de futuro para seguir percibiéndolo».

(31) Cfr. CASTILLO BLANCO, Federico A., El sistema retributivo en la función pública española. Marcial Pons, Madrid, 2002. Citado por VAQUER CABALLERÍA, Marcos. «El criterio de la eficiencia en el Derecho Administrativo", en Revista de Administración Pública, n. ${ }^{\circ}$ 186, 2011, pp. 91-135. p. 113.

(32) CASTILLO BLANCO, Federico A., "Luces y sombras del complemento de productividad: ¿un concepto retributivo inaplicado?", en Justicia administrativa: Revista de Derecho Administrativo, n. ${ }^{\circ} 8,2000$, pp. 5-24, CONSUEGRA GINER, Francesc, "A vueltas con el complemento de productividad fijo y periódico", en El Consultor de los Ayuntamientos y de los Juzgados, n. ${ }^{\circ} 3,2013$, pp. 289-297. GIL GUILLÉN, Enrique, "La desnaturalización del complemento de productividad y su «mutación» en una retribución fija», en, n. ${ }^{\circ} 21,2011$, pp. 2495-2505. Por su parte, la STSJ de Madrid n. ${ }^{\circ} 574 / 2009$, de 2 de junio (FJ $3 .^{\circ}$ y $4 .^{\circ}$ ) critica a la Dirección General de la Policía una Instrucción reconociendo el complemento en casos tan incomprensibles como "vacaciones, permisos por matrimonio, asuntos propios, traslado de domicilio habitual, asistencias a cursos, cumplimiento de deberes inexcusables o asistencia a exámenes». Además, recordando la STSJ de la Comunidad Valenciana $n .^{\circ} 601 / 1999$, de 2 de junio, reitera que «no se atisba la razón jurídica válida que pueda justificar el por qué se excluye la percepción del complemento de productividad en casos de enfermedad no profesional o accidente común, causas de ausencia al trabajo evidentemente involuntarias, y sin embargo se reconoce el derecho a la percepción del mismo en situaciones tan variopintas como algunas de las descritas con anterioridad, como por ejemplo los permisos por asuntos propios, en los que también se produce una ausencia al trabajo pero que, además, es voluntaria». 
bién se ha dado el caso de que, en virtud de la doctrina de los actos propios, los Tribunales hayan reconocido ese carácter objetivo, fijo en la cuantía y periódico en el tiempo, extendiendo la interpretación del mismo cuando lo propio habría sido unificar el criterio de condenar ese tipo de prácticas (33). Hubiese sido una oportunidad única que el EBEP incluyese esta doctrina de manera definitiva para despejar dudas y saldar definitivamente la cuestión.

Será pues, un reto previo o coetáneo a la instauración de modelos eficientes de evaluación del desempeño que se logren superar los problemas inherentes al complemento de productividad y se adopte, al fin, una postura decidida a favor del aprovechamiento de las ventajas que aporta un sistema que permite medir el desempeño para poder conectarle consecuencias lógicas y objetivas en materia retributiva. Sin embargo, estamos de acuerdo con autores como VAQUER CABALLERÍA cuando consideran que al no haberse establecido en el EBEP la forma en que se debe llevar a cabo la evaluación "hace posible que los sistemas se desnaturalicen o no articulen las necesarias garantías contra la arbitrariedad y que el complemento de productividad siga degenerando en una mayor retribución al puesto o a los méritos del funcionario, y no a su desempeño" (34).

Pero queda una última cuestión no menos problemática, pues hemos de recordar que la Disposición Transitoria Primera del EBEP (35) establece la garantía de indemnidad retributiva, no entendiéndose bien cómo puede crearse un modelo novedoso de retribución del desempeño, cuya intención es evitar los problemas tradicionales que venimos apuntando, y al mismo tiempo se mantiene el marco salarial anterior, apoyada por cierta Jurisprudencia, creándose situaciones insostenibles en el nuevo modelo. O se reconduce este escenario partiendo prácticamente de cero para solucionar los problemas del complemento de productividad, eliminándolo a priori y estableciendo criterios objetivos realmente ajustados al ordenamiento, lo cual podría suponer la vulneración de sus derechos adquiridos, o se perpetúa una situación insostenible y todo lo que pretende el EBEP en esta materia no habrá servido de nada.

(33) PADILLA RUIZ, Pedro, «El complemento de productividad y la evaluación del desempeño en la Ley $7 / 2007$. Hacia la calidad en la gestión pública", en EL Consultor de los Ayuntamientos y de los Juzgados, n. ${ }^{\circ} 17,2008$, pp. 2867-2886. p. 2.869.

(34) VAQUER CABALLERÍA, Marcos, "El criterio de la eficiencia en el Derecho Administrativo», en Revista de Administración Pública, n. ${ }^{\circ}$ 186, 2011, pp. 91-135. p. 113.

(35) El primer apartado de la citada Disposición establece: «El desarrollo del presente Estatuto no podrá comportar para el personal incluido en su ámbito de aplicación, la disminución de la cuantía de los derechos económicos y otros complementos retributivos inherentes al sistema de carrera vigente para los mismos en el momento de su entrada en vigor, cualquiera que sea la situación administrativa en que se encuentren". 
Quizás la solución vendría dada al desarrollarse el EBEP, mediante la sustitución paulatina de esos complementos anteriores por otros adaptados al mismo y a los criterios de la evaluación del desempeño, a través de complementos transitorios y absorbibles.

\section{Un sistema de carrera artificial que no ha cumplido su función}

Otro problema bien conocido que han venido sufriendo nuestras Administraciones ha sido la existencia de un modelo de carrera profesional insuficientemente desarrollado y que se ha desvirtuado hasta hacerlo inútil en muchos casos. De manera similar a lo que ocurriera con el complemento de productividad, lo que se creó como una institución lógica en cualquier sistema de gestión de personas con el fin de motivarlas haciendo posible su progreso profesional, se convirtió en un modelo teóricamente muy elemental al no prever un verdadero sistema de mérito profesional (36) enlazado con una planificación y gestión del personal coherentes con las necesidades de aquella.

La mala configuración del sistema de carrera y las prácticas que han llevado a cabo muchas Administraciones tuvieron como resultado un continuo trasiego de funcionarios por los diferentes puestos de trabajo sin contar previamente con el diseño de una carrera profesional que satisficiera las necesidades de unas y otros, como señala FUENTETAJA PASTOR (37). Esto ha generado una artificiosa movilidad no siempre deseada pero que se veía por el funcionario como necesaria si quería progresar de alguna manera, aunque fuese por motivos meramente económicos. Otra consecuencia de este mecanismo ha sido la falta de la idoneidad o capacitación adecuada de quien aspiraba al nuevo puesto debido a que el hecho de desempeñar uno de categoría inferior durante cierto tiempo, unido a la superación de unas pruebas generalmente memorísticas, no garantiza necesariamente que la persona tuviese las competencias habilitantes requeridas para ocupar puestos de mayor responsabilidad.

Todo ello ha llevado también a un contraproducente sobredimensionamiento de plantillas, unido a un mayor coste económico para las Adminis-

(36) La evolución y características del sistema de mérito en la función pública han sido estudiados por PRATS CATALÁ, Joan, "Los fundamentos institucionales del sistema de mérito: la obligada distinción entre función pública y empleo público», en Documentación Administrativa, n. ${ }^{\circ} 241,1994$, pp. 11-59. FÉREZ FERNÁNDEZ, Manuel, «El sistema de mérito en el empleo público: principales singularidades y analogías respecto del empleo en el sector privado", en El Consultor de los Ayuntamientos $y$ de los Juzgados, n. ${ }^{\circ} 17$, pp. 61-123.

(37) FUENTETAJA PASTOR, Jesús Ángel, "La carrera horizontal en el empleo público: una oportunidad para las Administraciones parlamentarias", en Cortes de Valencia. Anuario de derecho parlamentario, n. ${ }^{\circ} 22,2009$, pp. 61-75. p. 69. 
traciones Públicas, al que también hace alusión el Informe de la Comisión (38). La ineficiencia venía dada porque, como se comprenderá, ese mayor coste a través de la compensación por avanzar en la carrera en ocasiones no comportaba mayores responsabilidades sino simplemente, como se dijo, permitir que el funcionario progresara de manera artificiosa.

El problema no acaba aquí pues hay que tener en cuenta que quienes ya habían alcanzado o se encontraban en los puestos más altos veían casi imposible seguir avanzando, por lo que sus posibilidades de progreso profesional quedaban generalmente limitadas a cobrar los trienios. Esta situación se ve de manera más palpable en las Administraciones Locales de menor tamaño, con pocos puestos de los Subgrupos A/A1 o A2, y en las que no existen realmente muchas posibilidades de promoción (39).

En definitiva, el modelo tradicional de carrera ha constituido otro obstáculo para lograr una verdadera gestión de personas que tuviera en cuenta la valía de los empleados públicos y su necesidad de progreso profesional, al tiempo de considerar las necesidades de la propia Administración, lo que ha llevado a la falta del suficiente incentivo y motivación, un mayor coste económico y de talento $y$, sobre todo, una inexistente y grave desconexión entre lo organizativo y la gestión del personal.

La evaluación del desempeño trata de solventar estas carencias, brevemente apuntadas, al permitir enlazar los resultados de la medición del rendimiento profesional, que incluyen la adquisición de competencias profesionales, con el progreso en los puestos que mejor se adapten al perfil que va adquiriendo el empleado. Tampoco hay que perder de vista la novedad que ha supuesto la carrera horizontal como medida inteligente para soslayar los innumerables problemas que ha traído consigo el modelo tradicional, permitiendo que el funcionario progrese sin cambiar de puesto, aunque también hay que mencionar las críticas recibidas por parte de algunos autores como PARADA VÁZQUEZ, que ha denominado al nuevo modelo como la "carrera de los inmóviles», donde el requisito básico es «no moverse del mismo puesto de trabajo [...] sin asumir nuevas responsabilidades" y en la que acabarán por crearse niveles o grados que se adquirirán por el paso del tiempo sin tener una evaluación negativa (40).

(38) SÁNCHEZ MORÓN, Miguel, CASES MÉNDEZ, José Ignacio, et al., Informe de la Comisión para el estudio del Estatuto Básico del Empleado Público. INAP [versión electrónica], Madrid, 2005. N. ${ }^{\circ}$ 34. p. 84

(39) Sobre carrera administrativa en la Administración local, LAGUNA DE PAZ, José Carlos. "La carrera administrativa en la Función Pública Local: Promoción y movilidad", en Revista de estudios de la administración local y autonómica, n. ${ }^{\circ} 308,2008, \mathrm{pp} .47-62$.

(40) PARADA VÁZOUEZ, José Ramón, Derecho Administrativo. Vol II. Organización y empleo públi-

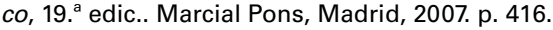




\section{La desmotivación del empleado público}

Ya hemos mencionado en los apartados anteriores el grave problema de desmotivación del empleo público que arrastran nuestras Administraciones desde hace décadas, lo que demuestra la cantidad de factores que lo generan y su importancia en el logro de un empleo público eficaz y eficiente; cuestión que parece comenzar a tenerse en cuenta con el EBEP y en la que inciden diversos autores (41).

La desmotivación tiene unos efectos claros en la reducción de la productividad y de la innovación, en la pérdida de talento, en un inadecuado trato al ciudadano (42), en una mala imagen proyectada frente a este. Se plasma, en suma, en la falta de implicación con el servicio público y en absentismo. Si tenemos en cuenta que la motivación se encuentra íntimamente relacionada con los incentivos de todo tipo que las organizaciones ponen a disposición de sus empleados, así como con la cultura organizacional existente, podemos concluir que, lejos de mejorar los resultados de la Administración, una mala gestión del personal lleva aparejada la pérdida de implicación con el trabajo. En tal sentido hay que recordar que en la gestión de personas se encuentra el núcleo de todos esos elementos, causas y efectos de la motivación.

Debemos partir de la consideración de que en el conjunto de nuestras Administraciones Públicas no han existido verdaderas políticas de personal ni, mucho menos, una gestión integral de personas; lo normal ha sido la mera administración de recursos humanos (selección, nóminas, seguros sociales, bajas...), como recuerdan PEIRÓ SILLA y CORTÉS CARRERES (43), pero sin pensar más allá del día a día. Asimismo, cabe recordar la práctica inexistencia de relación entre las políticas retributivas y las formativas, ni entre estas y la carrera. Y para colmo y como hemos indicado, la productividad y las recompensas no han ido de la mano y aquellas se han limitado a las meramente pecuniarias, olvi-

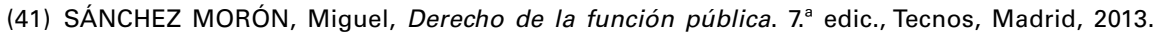
p. 57. SARMIENTO LARRAURI, José Ignacio, "La carrera de los funcionarios en el Estudio del Estatuto Básico del Empleado Público", en Actualidad administrativa, n. ${ }^{\circ}$ 2, 2006, pp. 143-152. BARRERA PICÓN, Ana. "La importancia de la motivación laboral en el empleado público: cómo potenciarla", en CEF Revista de trabajo y seguridad social: Comentarios, casos prácticos: recursos humanos, n. ${ }^{\circ} 384,2015$, pp. 239-272. ROBINA RAMÍREZ, Rafael, Condicionantes sociolaborales de los empleados públicos: Motivación y satisfacción laboral en la Administración regional extremeña. Universidad de Extremadura. Servicio de Publicaciones, Tesis Doctoral, 2002.

(42) MOREY JUAN, Andrés. La función pública: necesidad de un análisis conceptual y de la revisión del sistema de libre designación. INAP, Madrid, 2004. p. 20.

(43) PEIRÓ SILLA, José M., CORTÉS CARRERES, José V., et al., Productividad y gestión de recursos humanos en las Administraciones Públicas. Fundación de las Cajas de Ahorros, Madrid, 2012. p. 231. 
dando otros factores intrínsecos de motivación y de gestión del reconocimiento (44).

Por si fuera poco, el sistema retributivo también ha sido "cicatero» (45), con congelaciones o subidas salariales por debajo del IPC y que vienen de antiguo, situación que aún se manifiesta sin que exista apariencia de verse solucionada. Todos estos factores provocan una clara sensación de injusticia que lleva a la desconexión mental del trabajo e incluso al absentismo laboral. Podemos decir sin temor a equivocarnos que el empleo público, en este ámbito, ha venido sufriendo un tradicional trastorno de déficit de atención que ha afectado a los resultados de la propia Administración, sin perder de vista otros importantes problemas que esta arrastra.

Quizás otra causa más profunda, al margen de las limitaciones legales existentes, haya sido el desconocimiento de la importancia de la motivación y su recompensa por parte de la Administración y de los gestores públicos, pues en la práctica a los mejores empleados, a quienes se muestran más dispuestos con el servicio público, se les premia con más carga de trabajo por ser los más eficientes, mientras que a los peores empleados, a los que ponen mala cara ante cualquier encargo se procura no «molestarlos».

El problema también tiene que ver con la búsqueda de la mejora continua a través de la optimización de los procedimientos y la innovación, materia en la que el talento y la aportación de ideas por parte de los empleados públicos puede hacer mucho bien pero no se ha considerado en absoluto. Recordemos que son ellos quienes aplican el procedimiento y conocen de primera mano las necesidades de los ciudadanos y los problemas que se producen en el día a día. No tenerlos en cuenta, no empoderarlos en definitiva, está provocando también desmotivación al no sentirse valorados en sus propias organizaciones y que no se les escuche cuando lo cierto es que pueden aportarles mucho.

A estos factores hay que unirles el desprestigio social de la función pública, que ha mermado su autoestima. Los ciudadanos no perdonan la falta de resultados y la ineficiencia; y puesto que los empleados públicos son la "primera» línea entre la Administración y aquellos, la culpa de casi todos sus males recae en ellos, como recuerda BELTRÁN VILLALVA(46);

(44) PADILLA RUIZ, Pedro, "La gestión del reconocimiento en la Administración Pública", en Estudios financieros. Revista de Trabajo y Seguridad Social: Comentarios, casos prácticos: recursos humanos., n. ${ }^{\circ} 364,2013$, pp. 189-206.

(45) ROMÁN RIECHMANN, Carmen, SÁNCHEZ MORÓN, Miguel, et al., "Líneas de reforma del empleo público", SAINZ MORENO, Fernando (Dir.), en Estudios para la reforma de la Administración Pública. INAP, Madrid, 2004, pp. 479-516. p. 505.

(46) BELTRÁN VILLALVA, Miguel, La productividad de la Administración española: un análisis comparativo. Instituto de Estudios de Prospectiva, Madrid, 1991. Citado por MARTíNEZ, Rafael y JANÉ, Pep, "Tipología de sistemas de evaluación del empleado público», en Revista Buen Gobierno, n. ${ }^{\circ} 13$, 2012, pp. 110-143. 
lo que también se produce a consecuencia de una mal entendida inamovilidad en la función pública, sobre todo en épocas de crisis.

Más recientemente esa misma crisis ha dado un nuevo golpe en la motivación a través de las conocidas medidas anticrisis y de mejora de la productividad, que para JIMÉNEZ ASENSIO o GORRITI BONTIGUI han aumentado la herida de un maltrecho empleo público (47) a la vez que ha demostrado la falta de liderazgo por parte del Estado a la hora de implantar las previsiones del Estatuto (48).

Por fin el EBEP menciona la motivación y la relaciona con la evaluación del desempeño, pues esta es, ciertamente, una herramienta que a través de sus resultados permitirá completar un sistema que ha venido produciendo grandes desajustes, teniendo en cuenta que el Informe de la Comisión considera la evaluación como "un factor fundamental de mejora de la motivación», adquiriendo incluso un carácter de esencialidad por cuanto constituye por sí uno de los fines de la misma, como deja clara la Exposición de motivos del texto original del EBEP, siguiendo los consejos del Informe de la Comisión (49).

La evaluación no solamente mejorará la motivación del empleado público por sus efectos intrínsecos al permitirle conocer cómo está desempeñando su trabajo, lo que de por sí ayuda en el logro personal y está demostrado por la psicología del trabajo. También tiene un evidente efecto motivador de manera indirecta al enlazar los resultados de la medida del desempeño con unas consecuencias en el salario, la carrera, la formación, etc., aunque debemos pensar en sus beneficios más allá -inclusode los establecidos en el artículo 20 EBEP y considerar otros ámbitos, pues los usos y efectos de la evaluación en otras áreas de la gestión del personal (50) son evidentes y hay que explorarlos para conseguir no solo la motivación personal sino la calidad total de nuestras Administraciones Públicas.

(47) JIMÉNEZ ASENSIO, Rafael, "¿Qué hacer? El empleo público local ante la crisis: políticas de ajuste en un marco de reformas", en El empleo público local ante la crisis. Serie Debates, n. ${ }^{\circ} 2,2011$, pp. 13-87. GORRITI BONTIGUI, Mikel, "Un sistema de reforma del empleo público alternativo a los recortes de personal", en Revista Vasca de Gestión de Personas y Organizaciones Públicas, n. ${ }^{\circ} 4$, 2013, pp. 8-23.

(48) JIMÉNEZ ASENSIO, Rafael, «Una nueva ley de empleo público para Euskadi: inercia versus innovación", en Revista Vasca de Gestión de Personas y Organizaciones Públicas, n. ${ }^{\circ}$ 1, 2011, pp. 11-34. p. 17.

(49) SÁNCHEZ MORÓN, Miguel, CASES MÉNDEZ, José Ignacio, et al., Informe de la Comisión para el estudio del Estatuto Básico del Empleado Público. INAP [versión electrónica], Madrid, 2005. N..$^{\circ}$ 47. p. 107. Además, la motivación queda curiosamente enlazada en el Informe en otros aspectos también relacionados con la evaluación como la carrera (junto con la satisfacción; p. 102) o la formación (p. 114).

(50) PADILLA RUIZ, Pedro, Gestión del empleo público. La evaluación del desempeño en la mejora de la eficiencia administrativa. Bosch Editor, Barcelona, 2016. pp. 426 y ss. 


\section{La olvidada institución de la formación del empleado público}

La formación constituye otra de las áreas de la gestión del personal que no ha sido tratada como debiera en la Administración española. Se le ha prestado poca atención, cuando no ha sido totalmente ninguneada, siendo el empleado público quien debía preocuparse por mantener sus capacidades formativas actualizadas a pesar de la importancia capital que tiene dentro del contexto de un empleo público eficaz, eficiente y de calidad para la consecución de los objetivos administrativos(51). Así también lo veía el Informe de la Comisión al considerar la necesidad de mantener un sistema de "formación profesional continua y el reciclaje profesional» para "conseguir sus objetivos permanentes de eficacia y de modernización» (52).

Por desgracia, podemos traer a colación también aquí como causa del problema de la formación en el empleo público su falta de conexión con las políticas generales de gestión del personal, pues las necesidades formativas deben detectarse no solo por los empleados sino sobre todo por la propia organización a través de la evaluación del desempeño. Es así como se conocen las carencias en este ámbito y como se pueden aportar las soluciones que permitan un rendimiento mejor, siempre conectado a los objetivos generales y a una planificación estratégica que dirija los esfuerzos formativos hacia el interés organizativo. Como indica GONZÁLEZHABA GUISADO, la formación no tiene otra finalidad que acomodar el empleo público a los cambios de una Administración cada vez más compleja, tecnificada y en constante progreso (53).

Podemos decir, como en los apartados anteriores, que el legislador ya preveía en alguna medida un modelo formativo, si bien también de manera tímida. Por ejemplo, el artículo 65 de la Ley de Funcionarios Civiles del Estado (LFCE), se preocupaba al menos de que los superiores jerárquicos conocieran las aptitudes de sus subordinados con el fin de proponer actividades formativas para mejorar sus resultados(54). Ello supuso

(51) PUCHOL MORENO, Luis, Dirección y gestión de recursos humanos. 7. ${ }^{a}$ edic., Díaz de Santos, Madrid, 2012. p. 206.

(52) SÁNCHEZ MORÓN, Miguel, CASES MÉNDEZ, José Ignacio, et al., Informe de la Comisión para el estudio del Estatuto Básico del Empleado Público. INAP [versión electrónica], Madrid, 2005. p. 71. Esos instrumentos, mencionados por la Comisión, son los Registros de Personal, la Oferta de Empleo Público y las Relaciones de Puestos deTrabajo.

(53) GONZÁLEZ-HABA GUISADO, Vicente María, "La formación permanente de los funcionarios públicos", en Documentación Administrativa, n. ${ }^{\circ} 139,1971$, pp. 85-103. p. 97. Léase también a TOÑA GÜENAGA, Fernando, CALONGE CRESPO, Iñaki, et al., Estatuto básico del empleado público y márgenes de configuración del legislador vasco para su desarrollo. IVAP, Oñati [Guipúzcoa], 2007. p. 26.

(54) Art. 65 LFCE: «Los Jefes solicitarán periódicamente el parecer de cada uno de sus subordinados inmediatos acerca de las tareas que tienen encomendadas y se informarán de sus aptitudes profesionales con objeto de que puedan asignarles los trabajos más adecuados y de llevar a cabo un plan que complete su formación y mejore su eficacia». 
formalizar la necesidad de mantener una constante comunicación entre los superiores y los subordinados, donde aquellos conocieran mejor las aptitudes de estos; cuestión que sin duda coadyuva en la tarea de proponer las medidas formativas necesarias para la mejora de la calidad del servicio público (55).

A pesar de que la LMRFP mantuvo vigente ese artículo, los gestores en materia de personal no han sabido aprovechar sus posibilidades al no ver la importancia que la formación tiene en dicha gestión y mucho menos en los resultados de la organización en su conjunto. Por el contrario, ha sido el empleado público quien, como dijimos, ha solicitado la formación que ha considerado conveniente o necesaria a su puesto en función de su experiencia diaria, contando en no pocas ocasiones con las reticencias de los superiores cuando no con una directa oposición, al considerarse a esta institución muchas veces como un medio del que se sirve el empleado para ausentarse del trabajo más que como un verdadero canal de mejora individual y organizacional.

En la práctica, las Administraciones Públicas o los sindicatos (a través, por ejemplo, de los Acuerdos Gobierno-Sindicatos, tripartitos o similares) han ofertado cursos, itinerarios formativos, etc., teniendo solo en cuenta la demanda de ediciones anteriores o las propuestas de los propios empleados públicos, pero sin considerar las necesidades reales de las Administraciones, con lo que la ineficiencia, las corruptelas y la muerte del sistema estaba prácticamente servida.

EI EBEP pone por fin en valor la institución de la formación, aunque parece que de manera ciertamente tímida aún, pues al margen de considerarla como un derecho-deber individual del empleado público (56) y mencionarla como efecto de la evaluación del desempeño, pocas novedades más aporta. Por otra parte, si tenemos en cuenta el papel del superior jerárquico en la detección de necesidades formativas y la relación actual de la formación con la evaluación, surge un problema añadido con la figura de ese superior como evaluador. En efecto, como recuerdan ÁNGEL y GÓMEZ-POMAR RODRÍGUEZ, a la falta de preparación del superior para asumir el rol de evaluador o juez(57) se le une el de consejero o cuasi experto en materia de necesidades formativas, lo que sin duda exige ciertos conocimientos si de establecer planes de formación se trata. Sobre todo porque, como indica PUCHOL MORENO, la forma-

(55) Por su parte, el artículo 72 LFCE prevé la concesión de licencias remuneradas para realizar cursos de formación.

(56) Derecho reconocido en el artículo 14.g EBEP. Como deber se establece principalmente en el artículo 54.8 EBEP.

(57) ÁNGEL, Adriana, GÓMEZ-POMAR RODRíGUEZ, Julio, et al., La evaluación del desempeño en las Administraciones Públicas. Instituto de Empresa, Madrid, 2008. p. 98. 
ción no es un fin en sí mismo sino que los planes y políticas de formación han de ser coherentes con las políticas generales de la organización (58).

Sin perder de vista la buena intención del legislador al hacer recaer sobre el superior jerárquico la preocupación por esas aptitudes y la formación del empleado, le faltó quizás mayor previsión sobre la imprescindible comunicación y coordinación entre los jefes y el departamento de gestión de personal, al ser el superior jerárquico el nexo de unión entre el empleado y su correspondiente unidad administrativa con dicho departamento.

Otro obstáculo inherente a las dificultades apuntadas es que, una vez adquirida la formación, tampoco han existido medios para comprobar su éxito en la aplicación práctica al puesto de trabajo. Desde esta perspectiva hay que tener presente, con SISTERNAS, que al contrario de lo que suele pensarse la formación no significa necesariamente aprendizaje (aunque puede aplicarse para ello) sino que más bien su objetivo último es cambiar conductas o formas de actuar (59); esto es, que con aquella el empleado mejore el modo en que ejecuta su trabajo. Al cumplir la evaluación del desempeño el doble propósito de comprobar las carencias formativas y, posteriormente, los resultados en el desempeño de los conocimientos y aptitudes recibidos con ella, es fácil deducir que si no ha existido hasta ahora una herramienta como aquella tampoco ha cabido la posibilidad de medir hasta qué punto la formación obtenida se ha adaptado al puesto de trabajo, con lo cual el modelo existente no ha tenido realmente una construcción lógica ni mucho menos acabada dentro de un sistema de gestión de personal mínimamente organizado.

\section{Conclusiones}

EI EBEP ha supuesto una verdadera revolución en materia de modernización del empleo público; una norma anhelada y que ha aportado, quizás a partes iguales, novedosas y esperadas herramientas para mejorar una gestión del personal casi inexistente, como puede ser la propia evaluación del desempeño, pero al mismo tiempo nuevas dudas sobre su aplicación, ya que después de una década de su aprobación no parece haberse desarrollado suficientemente ni, mucho menos, implantado la evaluación.

(58) PUCHOL MORENO, Luis, Dirección y gestión de recursos humanos. 7. ${ }^{\text {a }}$ edic., Díaz de Santos, Madrid, 2012. p. 206.

(59) SISTERNAS, Xavier, "Formación para el cambio, cambio en la formación», en Gestión y Análisis de Políticas Públicas, n. ${ }^{\circ} 15,1999$, pp. 109-117. p. 110. 
La crisis económica fue una limitación importante para ello, pero también lo ha sido la falta del impulso y arrojo necesario para poner en marcha, aunque fuese poco a poco, los instrumentos que el EBEP aporta. En cuanto a la evaluación del desempeño hemos de reconocer que son muchos los problemas que viene arrastrando la Administración española y que es difícil atajarlos todos al mismo tiempo, pero lo que no se puede negar es que no se ha intentado, por lo general, solucionar o reducir al menos parte de las dificultades que se presentan al establecimiento de sistemas efectivos de evaluación del desempeño.

Muchas Administraciones siguen sin saber planificar, sin tener claros sus objetivos, su misión y visión de lo que deben ser como organizaciones de servicio público. Otras consideran la evaluación como algo impuesto por el legislador y que hay que aplicar necesariamente, sin pararse a pensar para qué la necesitan, dónde aplicarla ni cómo. Y, en fin, otras muchas no ven clara su implantación por las reticencias de los empleados o por el coste que supondría ponerla en práctica.

Si bien es un instrumento de aplicación obligatoria son diversos los obstáculos estructurales y las prácticas existentes en las Administraciones que hacen complicado poner en marcha la evaluación. Se da la paradoja de que algunos de esos mismos obstáculos tienen como solución la propia evaluación del desempeño. En cualquier caso, los gestores públicos son los primeros responsables de poner en marcha las novedades del EBEP, incluida aquella, pero deben tener el coraje suficiente para allanar el camino en la medida de lo posible.

La Administración debe saber hacia dónde dirigirse, aprender a trabajar por objetivos, planificar y utilizar técnicas hasta ahora más propias del entorno privado. No podemos pasar por alto que el legislador ha confiado en la evaluación y le ha dado, por fin, carta de naturaleza y con ello también, de alguna manera, ha puesto en valor todos esos conceptos relacionados con la transformación de nuestras organizaciones públicas para la consecución de la eficiencia.

Por tanto, hay que aprovechar la ocasión y no perder más tiempo, ponerse en marcha y remover esos obstáculos, ser innovador, crear cultura administrativa y sobre todo contar con el empleado público y su talento, motivarle, y diseñar sistemas de evaluación que sean útiles y ayuden realmente a mejorar la calidad del servicio público.

\section{Bibliografía}

ÁNGEL, Adriana, GÓMEZ-POMAR RODRÍGUEZ, Julio, et al., La evaluación del desempeño en las Administraciones Públicas. Instituto de Empresa, Madrid, 2008. 
ARENILLA SÁEZ, Manuel, Crisis y reforma de la Administración Pública. Netbiblo, Oleiros (Coruña), 2011.

ARENILLA SÁEZ, Manuel, "Legitimidad y eficacia de la Administración pública», en Gestión y análisis de políticas públicas, vol. Enero-Agosto, n. ${ }^{\circ}$ 26-27, 2003, pp. 71-102.

BACIGALUPO SAGGESE, Mariano, La discrecionalidad administrativa: estructura normativa, control judicial y límites constitucionales de su atribución. UNED, Tesis Doctoral, 1997.

BAÑÓN, Rafael, "La legitimidad de la Administración Pública», en BAÑóN, R. Y E. CARRILLO, (COMPS). La nueva Administración Pública. Alianza, Madrid, 1997.

BARRERA PICÓN, Ana, "La importancia de la motivación laboral en el empleado público: cómo potenciarla», en CEF Revista de trabajo y seguridad social: Comentarios, casos prácticos: recursos humanos, n. ${ }^{\circ} 384$, 2015, pp. 239-272.

BELTRÁN DE FELIPE, Miguel, Discrecionalidad administrativa y Constitución, Tecnos, Madrid, 1995.

BELTRÁN VILLALVA, Miguel, La productividad de la Administración española: un análisis comparativo. Instituto de Estudios de Prospectiva, Madrid, 1991.

BOLTAINA BOSCH, Xavier, "El empleo público local ante la crisis», en Debates locales, n. ${ }^{\circ} 2,2011$, pp. 288.

CASTILLO BLANCO, Federico A., El sistema retributivo en la función pública española. Marcial Pons, Madrid, 2002.

CASTILLO BLANCO, Federico A., "Los derechos retributivos de los empleados públicos", en SÁNCHEZ MORÓN, MIGUEL y CASTILLO BLANCO, FEDERICO A., Comentarios a la Ley del Estatuto Básico del Empleado Público. 2. ${ }^{a}$ edic., Lex Nova, Valladolid, 2008, pp. 229-321.

CASTILLO BLANCO, Federico A., "Luces y sombras del complemento de productividad: ¿un concepto retributivo inaplicado?», en Justicia administrativa: Revista de Derecho Administrativo, n. ${ }^{\circ} 8,2000$, pp. 5-24.

CONSUEGRA GINER, Francesc, "A vueltas con el complemento de productividad fijo y periódico", en El Consultor de los Ayuntamientos y de los Juzgados, n. ${ }^{\circ}$ 3, 2013, pp. 289-297.

CORTÉS CARRERES, J.V., Manual práctico de gestión de recursos humanos en la Administración Local. Dykinson, Madrid, 2001.

CUENCA CERVERA, J. Javier, Manual de dirección y gestión de recursos humanos en los gobiernos locales. INAP, Masdrid, 2012.

FÉREZ FERNÁNDEZ, Manuel, «El sistema de mérito en el empleo público: principales singularidades y analogías respecto del empleo en el sector privado", en Documentación Administrativa, n. ${ }^{\circ}$ 241, 1994, pp. 61-123.

FUENTETAJA PASTOR, Jesús Angel, "La carrera horizontal en el empleo público: una oportunidad para las Administraciones parlamentarias", 
en Cortes de Valencia. Anuario de derecho parlamentario, n. ${ }^{\circ} 22,2009$, pp. 61-75.

GIL GUILLÉN, Enrique, "La desnaturalización del complemento de productividad y su "mutación» en una retribución fija», en El Consultor de los Ayuntamientos y de los Juzgados, n. ${ }^{\circ} 21,2011$, pp. 2495-2505.

GONZÁLEZ-HABA GUISADO, Vicente María. "La formación permanente de los funcionarios públicos", en Documentación Administrativa, n. ${ }^{\circ} 139$, 1971, pp. 85-103.

GORRITI BONTIGUI, Mikel, «La Evaluación del Desempeño en las Administraciones Públicas Españolas», en Revista de Psicología delTrabajo y de las Organizaciones, vol. 23, n. ${ }^{\circ} 3,2007$, pp. 367-387.

GORRITI BONTIGUI, Mikel, "Un sistema de reforma del empleo público alternativo a los recortes de personal», en Revista Vasca de Gestión de Personas y Organizaciones Públicas, n. ${ }^{\circ} 4,2013$, pp. 8-23.

JIMÉNEZ ASENSIO, Rafael, “¿Qué hacer? El empleo público local ante la crisis: políticas de ajuste en un marco de reformas", en El empleo público local ante la crisis. Serie Debates, n. ${ }^{\circ} 2,2011$, pp. 13-87.

JIMÉNEZ ASENSIO, Rafael, "Una nueva ley de empleo público para Euskadi: inercia versus innovación", en Revista Vasca de Gestión de Personas y Organizaciones Públicas, n. ${ }^{\circ} 1,2011$, pp. 11-34.

LAGUNA DE PAZ, José Carlos, "La carrera administrativa en la Función Pública Local: Promoción y movilidad", en Revista de estudios de la administración local y autonómica, n. ${ }^{\circ} 308,2008$, pp. 47-62.

MANZANA LAGUARDA, Rafael, La nueva función pública: una injustificable demora. Especial referencia a la ley valenciana 10/2010. Tirant lo Blanch, Valencia, 2013.

MARTÍNEZ, Rafael y JANÉ, Pep, «Tipología de sistemas de evaluación del empleado público», en Revista Buen Gobierno, n. ${ }^{\circ} 13,2012$, pp. 110143.

MAURI MAJÓS, Joan, "Medidas de ajuste para hacer frente a la crisis en el empleo público local: una perspectiva desde la función pública", en Cuadernos de Derecho Local, n. ${ }^{\circ} 26$. Junio, 2011, pp. 55-86.

MOREY JUAN, Andrés, La función pública: necesidad de un análisis conceptual y de la revisión del sistema de libre designación. INAP, Madrid, 2004.

NIETO GARCÍA, Alejandro, "Un primer paso para la reforma de la Administración española», en BAENA DEL ALCÁZAR, MARIANO (DIR.), La reforma del Estado y de la Administración española. INAP, Madrid, 2013, pp. 163-184.

ORTEGA ÁLVAREZ, Luis, "¿Es posible desarrollar el EBEP en tiempos de crisis?", en FUENTETAJA PASTOR, Jesús Ángel y CANTERO MARTÍNEZ, Josefa (Dir.), Crisis económica y función pública. Aranzadi Thomson Reuters, Cizur Menor (Navarra), 2012, pp. 11-20. 
PADILLA RUIZ, Pedro, "El complemento de productividad y la evaluación del desempeño en la Ley 7/2007. Hacia la calidad en la gestión pública", en El Consultor de los Ayuntamientos y de los Juzgados, n. ${ }^{\circ} 17,2008$, pp. 2867-2886.

PADILLA RUIZ, Pedro, Gestión del empleo público. La evaluación del desempeño en la mejora de la eficiencia administrativa. Bosch Editor, Barcelona, 2016.

PADILLA RUIZ, Pedro, "La gestión del reconocimiento en la Administración Pública», en Estudios financieros. Revista de Trabajo y Seguridad Social: Comentarios, casos prácticos: recursos humanos., n. ${ }^{\circ} 364,2013$, pp. 189-206.

PALOMAR OLMEDA, Alberto, Derecho de la función pública. Régimen jurídico de los funcionarios públicos. Dykinson, Madrid, 2009.

PALOMAR OLMEDA, Alberto, "Impasse y deterioro del marco jurídico. ¿Habrá que cambiar el EBEP antes de aplicarlo?», en Revista Vasca de Gestión de Personas y Organizaciones Públicas, n. ${ }^{\circ} 3,2012$, pp. 78-93.

PALOMAR OLMEDA, Alberto, Planificación del empleo público e instrumentos de flexibilización y racionalización. $1 .^{a}$ edic., Lex Nova, Valladolid, 2015.

PARADA VÁZQUEZ, José Ramón, Derecho Administrativo. Vol II. Organiza-

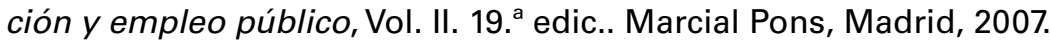

PAREJO ALFONSO, Luciano, Crisis y renovación en el Derecho Público. Edit. Ciudad Argentina, Buenos Aires, Madrid, 2003.

PAREJO ALFONSO, Luciano, Eficacia y Administración: tres estudios. INAP, Madrid, 1995.

PEIRÓ SILLA, José M., CORTÉS CARRERES, José V., et al., Productividad y gestión de recursos humanos en las Administraciones Públicas. Fundación de las Cajas de Ahorros, Madrid, 2012.

PRATS CATALÁ, Joan, "Los fundamentos institucionales del sistema de mérito: la obligada distinción entre función pública y empleo público», en Documentación Administrativa, n. ${ }^{\circ}$ 241, 1994, pp. 11-59.

PUCHOL MORENO, Luis, Dirección y gestión de recursos humanos. 7. ${ }^{a}$ edic., Díaz de Santos, Madrid, 2012.

RAMIÓ MATAS, Carles, Administración pública y crisis institucional: estrategias de reforma e innovación para España y América Latina. Tecnos, Madrid, 2015.

ROBINA RAMÍREZ, Rafael, Condicionantes sociolaborales de los empleados públicos: Motivación y satisfacción laboral en la Administración regional extremeña. Universidad de Extremadura. Servicio de Publicaciones, Tesis Doctoral, 2002.

RODRÍGUEZ ESCANCIANO, Susana, "Incidencia de la reforma laboral de 2012 sobre el empleo público. En especial, las medidas de reajuste de efectivos", en Boletín de Función Pública del INAP, n. ${ }^{\circ}$ 8, 2012, pp. 5-13. 
RODRÍGUEZ ESCANCIANO, Susana, "Los planes de empleo como medida de reestructuración administrativa: dificultades de aplicación práctica», en Las relaciones laborales en la reestructuración y el saneamiento de empresas : XVI Congreso Nacional de Derecho del Trabajo y de la Seguridad Social, 19 y 20 de mayo de 2005, Granada, 2006, pp. 297-322.

RODRÍGUEZ ESCANCIANO, Susana, "Posibilidades para el reajuste de efectivos en el ámbito público a la luz de la reforma laboral de 2012", en Cuadernos de derecho local, n. ${ }^{\circ} 31,2013$, pp. 40-69.

RODRÍGUEZ FERNÁNDEZ, Andrés, Dirección y gestión de los recursos humanos en las Administraciones Públicas. Instituto Andaluz de Administración Pública, Sevilla, 2001.

RODRÍGUEZ FERNÁNDEZ, Andrés, Los recursos humanos en las administraciones públicas. Tecnos, Madrid, 1995.

ROMÁN RIECHMANN, Carmen, SÁNCHEZ MORÓN, Miguel, et al., "Líneas de reforma del empleo público", en SAINZ MORENO, FERNANDO (DIR.), Estudios para la reforma de la Administración Pública. INAP, Madrid, 2004, pp. 479-516.

SÁNCHEZ MORÓN, Miguel, Derecho de la función pública, $7^{a}$ edic.. Tecnos, Madrid, 2013.

SÁNCHEZ MORÓN, Miguel, Discrecionalidad administrativa y control judicial. Tecnos, Madrid, 1994.

SÁNCHEZ MORÓN, Miguel, CASES MÉNDEZ, José Ignacio, et al., Informe de la Comisión para el estudio del Estatuto Básico del Empleado Público. INAP [versión electrónica], Madrid, 2005.

SARMIENTO LARRAURI, José Ignacio, "La carrera de los funcionarios en el Estudio del Estatuto Básico del Empleado Público", en Actualidad administrativa, $\mathrm{n}^{\circ}{ }^{\circ} 2,2006$, pp. 143-152.

SCHMIDT-ABMANN, Eberhard, "La legitimación de la Administración como concepto jurídico", en Documentación Administrativa, n. ${ }^{\circ} 234$, 1993, pp. 163-230.

SISTERNAS, Xavier, "Formación para el cambio, cambio en la formación», en Gestión y Análisis de Políticas Públicas, n. ${ }^{\circ} 15,1999$, pp. 109-117.

TAYLOR, Frederick Winslow, Management científico, $4{ }^{\text {a }}$ edic.. Orbis, Barcelona, 1986.

TEROL GÓMEZ, Ramón, "La Administración de las Comunidades Autónomas", en JAIME RODRÍGUEZ-ARANA MUÑOZ, (DTOR.), La Administración Pública española. INAP, Madrid, 2002.

TOÑA GÜENAGA, Fernando, CALONGE CRESPO, Iñaki, et al., Estatuto básico del empleado público y márgenes de configuración del legislador vasco para su desarrollo, IVAP, Oñati [Guipúzcoa], 2007.

VAOUER CABALLERÍA, Marcos, "El criterio de la eficiencia en el Derecho Administrativo", en Revista de Administración Pública, n. ${ }^{\circ} 186,2011$, pp. 91-135. 
VILLORIA MENDIETA, Manuel y DEL PINO MATUTE, Eloísa. Manual de gestión de recursos humanos en las Administraciones Públicas, 2. ${ }^{a}$ edic., Tecnos, Madrid, 2000.

Trabajo recibido el 19 de julio de 2017

Aceptado por el Consejo de Redacción el 20 de octubre de 2017 
LABURPENA: Hamarkada bat igaro da Enplegatu Publikoaren Oinarrizko Estatutua (EPOE) indarrean jarri zenetik, baina Administrazioa, enplegu publikoa eta jardueraren ebaluazioa modernizatzeko egin diren apustu nabarmenenak ez dira ezarri, eta ez da ahaleginik egin horiek gerora ezartzeko behar diren oinarriak jartze aldera.

Artikulu honetan, gure enplegu publikoan beharrezko aldaketa hori egitea galarazten jarraitzen duten alderdi nabarmenenak ikusiko ditugu, eta, zehazki, jardueraren ebaluazioaren behin betiko ezarpena ezartzea galarazten dutenak, egungo enplegu-ereduan hainbat hutsune eta mehatxu egotea ekartzen baitu horrek, gainditzeko zailak direnak (interes faltarengatik, ez berezko zailtasunengatik).

GAKO HITZAK: Jardueraren ebaluazioa. Enplegu publikoa. EPOE. Funtzio publikoa. Efizientzia. Jarduera.

RESUMEN: Ha transcurrido una década desde que entrara en vigor el Estatuto Básico del Empleado Público (EBEP) sin que una de sus más destacadas apuestas por modernizar la Administración y el empleo público, la evaluación del desempeño, se haya implantado ni se hayan intentado poner las bases necesarias para su posterior aplicación.

En este artículo repasaremos los aspectos más destacados que aún hoy continúan impidiendo ese necesario cambio de nuestro empleo público y en particular la aplicación definitiva de la evaluación del desempeño, que se traducen en una serie de defectos y amenazas del actual modelo de empleo difíciles de superar, aunque más por falta de interés que por dificultades intrínsecas.

PALABRAS CLAVE: Evaluación del desempeño. Empleo público. EBEP. Función pública. Eficiencia. Desempeño.

ABSTRACT: It has been a decade since the Basic Statute of the Public Employee was passed without job evaluation, one of its most important bets to modernize Administration and public employment, has been implemented, nor the necessary foundations for its later application have been tried to lay.

In this article we will review the more important aspects that still continue to impede this necessary change in our public employment and, especially, the ultimate application of job evaluation, that translate into a series of shortcomings and threats in the current employment model, difficult to overcome. Although it is due to a lack of interest more than intrinsic difficulties.

KEYWORDS: Job evaluation. Public employment. Civil Service. EBEP. Efficiency. Performance. 